\title{
CONSUMO DE APHIS GOSSYPII GLOVER, 1877 E MYZUS PERSICAE (SULZER, 1776) INFECTADOS COM FUNGOS ENTOMOPATOGÊNICOS POR ORIUS INSIDIOSUS (SAY, 1832) (HEMIPTERA, ANTHOCORIDAE)
}

\section{E.S. Loureiro'; A. Moino Júnior ${ }^{2}$}

${ }^{1}$ Universidade Federal da Grande Dourados, Faculdade de Ciências Biológicas e Ambientais, CP 533, CEP 79804-970, Dourados, MS, Brasil. E-mail: lis_loureiro@yahoo.com.br

\section{RESUMO}

\begin{abstract}
As espécies de pulgões Aphis gossypii e Myzus persicae são cosmopolitas e polífagas, causando prejuízos em plantas cultivadas. Foi avaliado o consumo de A.gossypii e M. persicae, infectados com fungos entomopatogênicos por Orius insidiosus. No centro de placas de Petri foi colocado um disco de 4,5 cm de diâmetro de folha de algodão (para A.gossypii) e um disco de $4,5 \mathrm{~cm}$ de diâmetro de folha de pimentão (para M. persicae). A inoculação dos fungos (Beauveria bassiana, Metarhizium anisopliae, Isaria fumosorosea e Lecanicillium lecanii) foi feita através da adição de $1 \mathrm{~mL}$ das suspensões fúngicas $1,0 \times 10^{5}$ e 1,0 $\times 10^{7}$ conídios/mL sobre a placa de Petri. Os pulgões foram oferecidos a uma fêmea do predador, liberada na placa em diferentes períodos de tempo após a inoculação, além de um tratamento no qual a fêmea do predador foi liberada com os pulgões mortos, já em fase de conidiogênese. As fêmeas do predador foram retiradas após 24 horas da liberação e, em seguida, foi avaliado o consumo de pulgões. O consumo foi significativamente inferior decorridas 24 horas da inoculação, quando comparado com o a testemunha, para as duas espécies de pulgões estudadas. $\mathrm{O}$ consumo de pulgões foi menor nas concentrações testadas no período de $24-48$ horas que o consumo da testemunha. Após 72 horas da inoculação e após conidiogênese, não foi observado consumo de pulgões pelo predador para as duas concentrações, evidenciando, dessa forma, a capacidade discriminatória do predador, sendo capaz de reconhecer a presa infectada pelo patógeno.
\end{abstract}

PALAVRAS-CHAVE: Beauveria bassiana, Metarhizium anisopliae, Isaria fumosorosea e Lecanicillium lecanii entomopatógenos, predador, pulgões.

\begin{abstract}
CONSUMPTION OF APHIS GOSSYPII GLOVER, 1877 AND MYZUS PERSICAE (SULZER, 1776) INFECTED WITH ENTOMOPATHOGENIC FUNGI BY ORIUS INSIDIOSUS (SAY, 1832) (HEMIPTERA, ANTHOCORIDAE) The species of aphids Aphis gossypii and Myzus persicae are cosmopolitan and polyphagous, causing damage to cultivated plants. The present study evaluated the consumption of A. gossypii and M. persicae infected with entomopathogenic fungi by $O$. insidiosus. Arenas were made with Petri dishes with a cotton foliar disk with $4.5 \mathrm{~cm}$ of diameter (for A. gossypii) and a pepper foliar disk (for M. persicae) at the center. The inoculation of the fungi (Beauveria bassiana, Metarhizium anisopliae, Isaria fumosorosea and Lecanicillium lecanii) was done through the addition of $1 \mathrm{~mL}$ of the fungal suspensions in the concentration of $1.0 \times 10^{5}$ and $1.0 \mathrm{x}$ $10^{7}$ conidia/mL on the Petri dish. The aphids were offered to a female of the predator, released to the dish at different periods of time after inoculation. There was also a treatment in which the female of the predator was released with dead aphids, already in the phase of conidiogenesis. The females were removed from the dishes 24 hours following release, followed by evaluation of aphids consumption. The consumption was significantly lower for releases 24 hours after inoculation, when compared with the control, for the two species of aphids studied. The consumption of aphids was lower for releases made 24-48 hours after inoculation, compared to the control. For releases 72 hours after inoculation, and after conidiogenesis, aphids consumption was not observed for the two concentrations, thus evidencing the discriminatory capacity of the predator, which is able to recognize the prey infected by pathogen.
\end{abstract}

KEY WORDS: Beauveria bassiana, Metarhizium anisopliae, Isaria fumosorosea and Lecanicillium lecanii entomopathogens, predator, aphid.

\footnotetext{
${ }^{2}$ Universidade Federal de Lavras, Departamento de Entomologia, Lavras, MG, Brasil.
} 


\section{INTRODUÇÃO}

Os pulgões, Aphis gossypii Glover, 1776 e Myzus persicae (Sulzer, 1776) (Hemiptera: Aphididae), são cosmopolitas e polífagos, causando prejuízos em plantas cultivadas em frutos e folhas através da sucção da seiva, a depreciação de frutos através do surgimento de fungos sobre o seu excremento (honey dew), a injeção de substâncias tóxicas e a transmissão de fitovírus em várias plantas cultivadas (PEÑAMARTíNES, 1992).

Os percevejos da família Anthocoridae são insetos de tamanho pequeno, os adultos medem menos que 4 $\mathrm{mm}$, sendo predadores em todos os instares, bem como os adultos (RAKAUSKAS, 1984). As espécies de percevejos do gênero Orius, predadores polífagos de pequenos artrópodos, como ácaros, tripes e ovos de lepidópteros, vêm se destacando devido ao grande potencial como agentes de controle biológico de importantes pragas, principalmente tripes e pulgões em cultivos protegidos (ISENHOUR;Y EARGAN, 1981). Devido a esse fato sua importância vem crescendo mundialmente, concomitantemente ao aumento da área plantada em cultivos protegidos, sendo as principais pragas (VAN LeNTEREN, 2000; FundERBURK et al., 2000; Mendes et al., 2005). Várias espécies deOrius sãoutilizadas em programas de controle biológico de tripes, moscabranca e pulgões em diversos países da Europa, Ásia, EUA e Canadá (Riudavets, 1995; Bueno, 2000).

O tipo de presa que Orius insidiosus (Say, 1832) (Hemiptera: Anthocoridae) consome tem grande influência s obre diversos aspectos do seu ciclobiológico. RICHARDS; SCHMIDT (1996) mostraram que a dieta pode interferir em parâmetros como o período de desenvolvimento, a longevidadedos adultos, a fecundidade, a viabilidade de ovos etc., podendo impedir seu desenvolvimento por completo. Também, segundo HolLiNG (1961), muitos fatores afetam a predação, como densidade de presas e predadores, características do ambiente, presença de alimento alternativo, reações de defesa da presa e características de ataque do predador. Assim, um aspecto importante da interação predador-presa está relacionado ao aumento do consumo de presas pelo predador e à capacidade de seu aumento populacional em função do aumento da densidade de presa, sendo esses fenômenos conhecidos, respectivamente, como resposta funcional e numérica.

O emprego de fungos entomopatogênicos, juntamente com insetos predadores, pode ser uma alternativa viável dentro do manejo integrado de pragas (MIP). Há relatos na literatura da ação conjunta do fungo Lecanicillium (= Verticillium) com alguns predadores no controle do pulgão Toxoptera citricidus (Kirkaldy, 1907) (Hemiptera, Aphididae) na Venezuela (Goetrel et al., 1990). Por outro lado, os insetos predadores exploram relativamente grandes áreas foliares em busca de suas presas e podem entrar em contato com conídios dos fungos depositados sobre as folhas, serem atingidos diretamente com o entomopatógeno no momento da aplicação ou no ato da disseminação do fungo pelo vento ou, ainda, interferirem no potencial de consumo de presas infectadas (FrançA et al., 2006).

Até o presente momento, não há nenhum estudo que demonstre a interação entre fungos entomopatogênicos e os antocorídeos, principalmente a espécie $O$. insidiosus produzida massalmente e comercializada em todo o mundo por quatro empresas (PLANET NAtural, 2001), sendo que, no Brasil,éa espécie mais abundante e de maior potencial para utilização em programas de controle biológico (BUENO, 2000; OLIVeira et al., 2008; De Bortoli et al., 2008). Assim, este trabalho teve por objetivo avaliar o consumo de $A$. gossypii e $M$. persicae, infectados com os fungos entomopatogênicos Beauveria bassiana (Bals.) Vuill., Metarhizium anisopliae (Metsch.) Sorok., Isaria fumosorosea (Wise) e Lecanicillium (= Verticillium) lecanii (Zimm.) Zare \& Gams, por O. insidiosus, verificando o efeito da concentração do fungo e da fase de desenvolvimento da doença na capacidade de consumo e no reconhecimento da presa infectada pelo predador.

\section{MATERIAL E MÉTODOS}

Os bioensaios foram conduzidos em sala climatizada a $25 \pm 1^{\circ} \mathrm{C}$, fotofase de 12 horas e umidade relativa de $70 \pm 10 \%$.

Foram utilizadas placas de Petri $(9 \mathrm{~cm}$ de diâmetro) contendo uma camada de $1 \mathrm{~cm}$ de meio ágarágua a $1 \%$. No centro dessas placas foi colocado um disco de $4,5 \mathrm{~cm}$ de diâmetro de folha de algodão (para A.gossypii) e um disco de $4,5 \mathrm{~cm}$ de diâmetro de folha de pimentão (paraM. persicae) (metodologia adaptada de Mesquita et al., 1999). A inoculação dos fungos (B. bassiana, M. anisopliae, I. fumosorosea e L. lecanii) foi feita através da adição de $1 \mathrm{~mL}$ das suspensões contendo Tween 80 sobre a placa de Petri contendo o disco foliar, utilizando pipetas esterilizadas. Após esse procedimento, 10 pulgões de 2 ínstar foram transferidos da criação para as placas nos diversos tratamentos. No tratamento testemunha, foi adicionada água esterilizada (1 $\mathrm{mL}$ ) nos discos foliares, da mesma forma feita para os demais tratamentos.

Fêmeas do predador (mantidas sem alimento por dois dias) foram liberadas nos discos foliares contendo os pulgões tratados com as suspensões fúngicas, sendo colocada uma fêmea por placa de Petri, em diferentes períodos de tempo após a inoculação (0-24, 
24-48, 48-72 e 72-96 horas), além de um tratamento no qual ela foi liberada com os pulgões mortos, já em fase de conidiogênese do fungo (esporulação). Após 24 horas de contato das fêmeas com os pulgões em cada tratamento, estas foram retiradas e efetuou-se a contagem dos pulgões.

Oexperimento foi constituído de duas suspensões fúngicas, de $1,0 \times 10^{5} \mathrm{e} 1,0 \times 10^{7}$ conídios/mL (LoureiRO; MOINO JÚNIOR, 2006) e um tratamento testemunha para cada fungo, para cada espécie de pulgão e para cada período de exposição, com cinco repetições cada, num esquema fatorial $3 \times 5$ (tratamento $x$ repetição). Os dados obtidos foram transformados para $(x+0,5)^{1 / 2}$ e submetidos à análise de variância e teste de Tukey $(P<0,05)$ para comparação entre as médias.

\section{RESULTADOS E DISCUSSÃO}

Pode-se observar que o consumo total de A.gossypii por $O$. insidiosus na testemunha diferiu dos demais tratamentos, nos diversos períodos após a inoculação, exceto no tratamento com o fungoI. fumosorosea (Wise) para as concentrações testadas $(4,60$ e 4,20, respectivamente, pulgões da espécie $A$. gossypii), decorridas 24-48 horas após a inoculação. A ingestão de lagartas de Alabama argillacea (Hübner, 1818) (Lepidoptera: Noctuidae) tratada com B. bassiana após 24 horas da infecção, por ninfas e adultos do percevejo predador Podisus nigrispinus (Dallas, 1851) (Hemiptera: Pentatomidae) não diferiu da testemunha, dados semelhantes foram encontrados no presente trabalho. Foi observado também $7,5 \%$ de mortalidade corrigida de ninfas por ocasião da emergência de adultos e não ocorreu mortalidade de adultos até 10 dias após alimentação (FrançA et al., 2006).

Não ocorreu consumo de A.gossypii nos tratamentos com 72 horas após a inoculação e após a conidiogênese de B.bassiana por O.insidiosus (Tabela 1).JAMES et al. (1995), estudando o efeito do fungo B. bassiana sobre Acyrthosiphon pisum (Harris, 1776) (Hemiptera: Aphididae) e o predador Hippodamia convergens Guérin-Méneville, 1842 (Coleoptera: Coccinellidae), em alfafa, verificaram que no início do desenvolvimento da cultura ocorreu uma redução de 75 a $93 \%$ na população do predador, não sendo observado nenhum efeito sobre este no final da safra.

Em cultivo de algodão foi aplicado $1,5 \times 10^{13}$ esporos/ha do isolado GHA de B. Bassiana (bioinseticida produzido em escala comercial pela Emerald. BioAgriculture, fórmula Mycotech Corp., Buttle, MT e registrado nos EUA), observando-se que durante a avaliação os insetos não alvos Orius, Nabis e Geocoris não foram afetados significativamente tanto na aplicação direta sobre, bem como o consumo das presas infectadas (JARONSKI et al., 1998). O mesmo isolado foi aplicado contra o predador Xylocoris flavipes (Reuter, 1875) (Hemiptera: Anthocoridae) não causando efeito letal sobre o predador nas concentrações de $2,7 \times 10^{7}, 2,6 \times 10^{6}$ e 2,6 $610^{5}$ conídios $/ \mathrm{cm}^{2}$ (DunKel; JARONSKI, 2003).

PESSOA et al. (2005) relataram que não houve efeito das suspensões $10^{4}, 10^{5}, 10^{6}, 10^{7}$ e $10^{8}$ conídios/mLdo fungo $B$. bassiana isolado (IBCB 66) sobre a viabilidade dos ovos e delarvas de primeiro e segundo ínstares de Chrysoperla externa Hagen, 1861 (Neuroptera: Chrysopidae). Observou-se diminuição na duração do terceiro ínstar de larvas tratadas com as suspensões de $10^{7}$ e $10^{8}$ conídios $/ \mathrm{mL}$. B. bassiana pode ser recomendado em aplicação conjunta com C. externa em programas de controle biológico de pragas, tendo em vista a baixa suscetibilidade desse predador ao entomopatógeno.

O predador distinguiu os pulgões infectados com M. anisopliae, pois, de maneira geral, observou-se um baixo consumo de pulgões mesmo nas primeiras horas após a inoculação, proporcionando diferença significativa no consumo por O. insidiosus de pulgões infectados e não infectados. Esses valores de consumo de pulgões são os mais baixos, dentre o consumo de pulgões infectados pelos demais fungos entomopatogênicos testados. Os valores foram próximos aos resultados obtidos em outros estudos para ninfas e adultos o predador $P$. nigrispinus alimentadas com A. argillacea infectada com M. anispoliae (FrANÇA et al., 2006). O baixo consumo de presas com qualidade inferior (infectadas com hifas e blastóporos e após a conidiogênese) é devido à ação de metabólicos tóxicos reconhecido pelo predador (COHEN, 2000). Após conidiogênese de M. anisopliae na maior e na menor concentração testada não ocorreu consumo de A. gossypii por O. insidiosus (Tabela 1).

No entanto, o predador $H$.convergens foi suscetível em pulverizações com B. bassiana, M. anisopliae e $I$. fumosorosea, mas imune a Nomuraea rileyi (Farlow) Samson (JAMES; LightHART, 1994).

Não ocorreu diferença significativa no consumo de pulgões entre as concentrações testadas e a testemunha, no intervalo 0-24 horas após a inoculação. Para a concentração de $10^{5}$ conídios/mL de $24-48$ horas da inoculação observou-se baixo consumo de pulgões infectados com ofungo I. fumosorosea (Tabela1). POPRAWSKI et al. (1997) observaram o efeito letal e subletal dos fungos entomopatogênicos $B$. bassiana e I. fumosorosea sobre o predador Serangiumparcesetosum Sicard, 1929 (Coleoptera: Coccinellidae), em condições de laboratório. Larvas alimentadas com presas contaminadas por B. bassiana apresentaram $86 \%$ de mortalidade. Já as larvas que se alimentaram com presas contaminadas $24,48,72$ ou 96 horas previamente, apresentaram $92,5,71,4,71,4$ e $44,0 \%$ de mortalidade, respectivamente. 


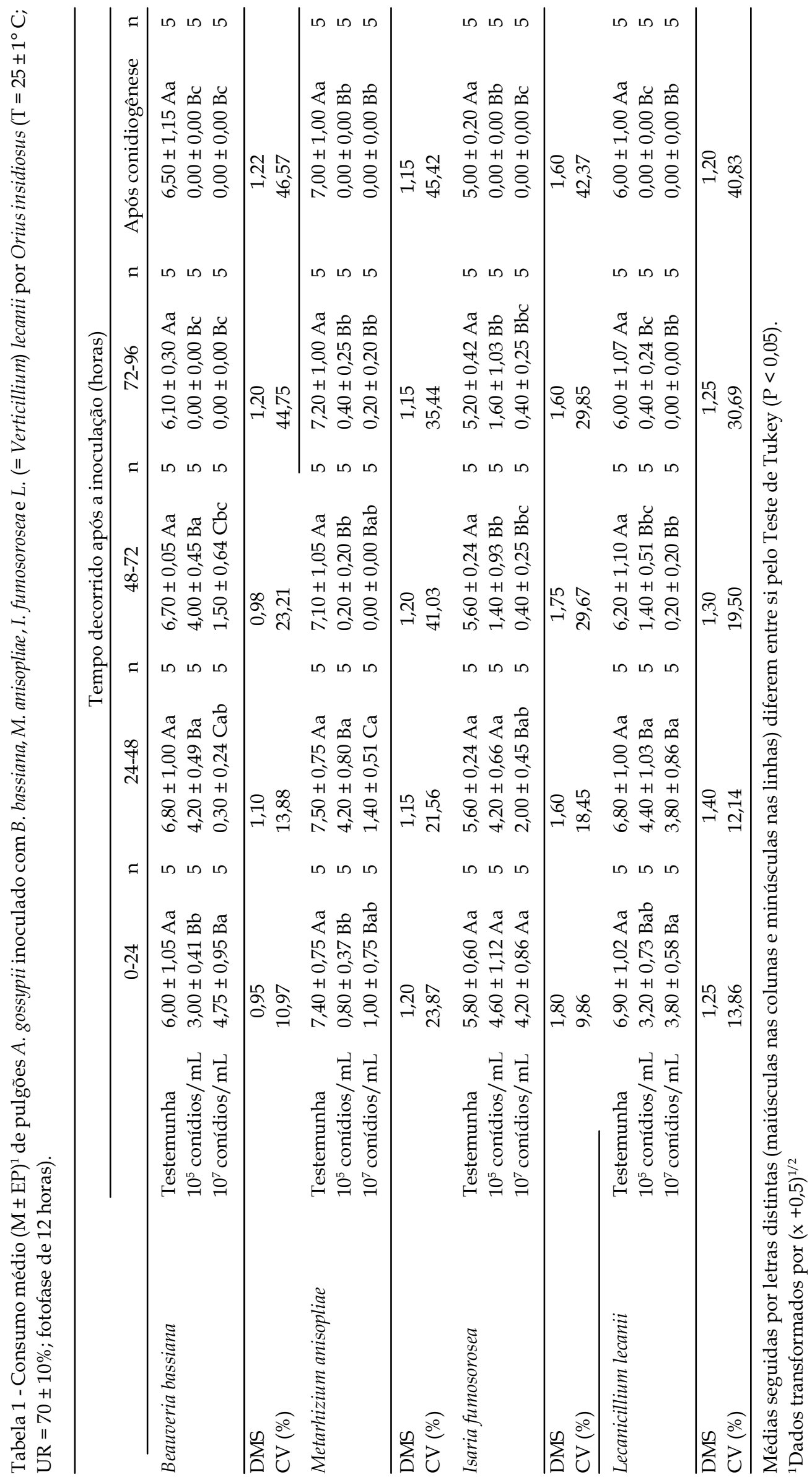




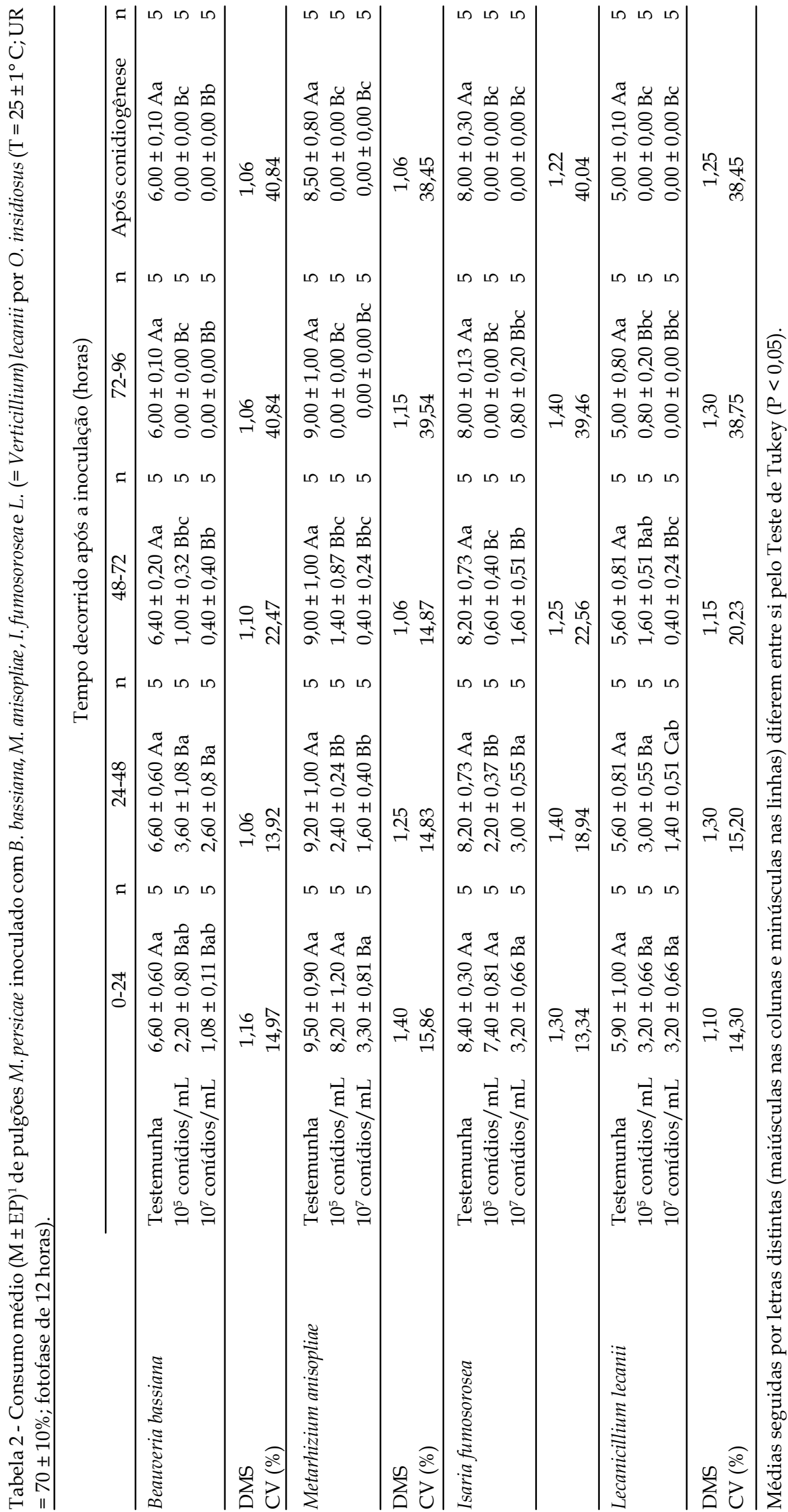


Para o consumo de pulgões infectados com $L$. lecanii (Zimm.) Zare \& W. Gams na concentração de $10^{5}$ conídios $/ \mathrm{mL}$ como na de $10^{7}$ conídios/mL do fungo L. lecanii, ocorreu diferença significativa em todos os intervalos após a inoculação (Tabela 1). L. lecanii pode ser utilizado em conjunto com o ácaro predador Phytoseiulus persimilis Athias-Henriot, 1957 (Acari: Phytoseiidae) para o controle da espécie de mosca branca Trialeurodes vaporariorum (Westwood, 1856) (Hemiptera: Aleyrodidae) sem afetar o predador (HALL, 1982).

Os resultados do experimento de avaliação do consumo de pulgões da espécie $M$. persicae infectados com o fungo entomopatogênico $B$. bassiana mostram que ocorreu diferença significativa entre o consumo de pulgões na testemunha e os pulgões infectados em todos os tempos decorridos após a inoculação (Tabela 2). Observa-se que decorridas 72-96 horas e após conidiogênese nenhum pulgão foi consumido pelo predador $O$. insidiosus, não ocorrendo diferença no consumo na concentração de $10^{5}$ conídios/mL após 0-24, 24-48 e 48-72 horas da inoculação. Na concentração de $10^{7}$ conídios/mL $\backslash$ ocorreu diferença significativa entre no intervalo 24-48 horas e os demais tempos de exposição, não ocorrendo diferença entre 0-24 horas. MAGALHÃEs et al.(1988) verificaram os efeitos de B. bassiana sobre os predadoresColeomegillamaculata De Geer, 1975 (Coleoptera: Coccinellidae) eEriopis connexa Germar, 1824 (Coleoptera: Coccinellidae). Os conídios foram aplicados diretamente sobre os predadores e sobre o substrato (feijoeiro) para alimentação de suas presas, Cerotoma arcuatus (Oliv., 1791) (Coleoptera: Chrysomellidae) e Empoasca kraemeri (Ross \& Moore, 1957) (Hemiptera: Cicadellidae). Foi observado que as espécies predadoras e suas presas são igualmente suscetíveis a $B$. bassiana quando os conídios são aplicados diretamente sobre os insetos. JáZoophthora radicans (Brefeld) Batko uma espécie de fungo altamente epizoótica não afetou os predadores.

Não ocorreu diferença no consumo entre os insetos infectados com uma suspensão de $10^{5}$ conídios / $\mathrm{mL}$ de $M$. anisopliae logo após a inoculação (0-24 horas) quando comparado com a testemunha. Não ocorreu diferença no consumo pelo predador de $M$. persicae entre as concentrações $10^{5}$ e $10^{7}$ conídios/ $\mathrm{mL}$, logo após a inoculação (0-24 horas). Verificouse também que o consumo de pulgões entre as concentrações de $10^{5}$ e $10^{7}$ conídios/mL no tempo 0-24 horas diferiu significativamente dos demais tempos estudados. Para 72 horas e após conidiogênese, o predador não consumiu nenhum pulgão infectado (Tabela 2).

Ocorreu diferença significativa no consumo de pulgões inoculados com I. fumosorosea quanto às con- centrações de $10^{5}$ e $10^{7}$ conídios/mL, para todos os parâmetros analisados (0-24, 24-48, 48-72, 72-96 horas e após conidiogênese) quando comparado ao da testemunha. Na concentração de $10^{7}$ conídios $/ \mathrm{mL} \mathrm{o}$ consumo de $M$. persicae nos intervalos 0-24, 24-48 diferiram dos tempos 48-72 horas, 72-96 horas e após conidiogênese (Tabela 2). GENEROSO (2002), trabalhando com B. bassiana (isolado CG 149) e comI. fumosorosea (isolado JAB 12), com concentrações de $10^{4}, 10^{5}, 10^{6}$, $10^{7}$ e $10^{8}$ conídios/mL, verificou que esses fungos foram seletivosàs larvas de primeiroe terceiroínstares de C. externa, provocando baixa mortalidade nesses estádios de desenvolvimento.

Observou-se baixo consumo de M. persicae com $L$. lecanii para todos os tempos decorridos após a inoculação, nas concentrações de $10^{5}$ e $10^{7}$ conídios / $\mathrm{mL}$. De maneira geral, não ocorreu diferença significativa até $24-48$ horas após a inoculação na concentração de $10^{5}$ conídios/mL indicando assim, um pequeno consumo de pulgões infectados. Através desses dados verifica-se a discriminação de presas infectadas e não infectadas pelo predadorO.insidiosus (Tabela 2).

Foi relatada porGoetteletal.(1990), experimentos realizados na Venezuela, a ação conjunta do fungo $L$. lecanii com os predadores Cicloneda sanguinea Linnaeus, 1763 (Coleoptera: Coccinellidae), Ocyptamus gastrostactus (Wiedemann, 1830) (Diptera: Syrphidae) e Zelus sp. Linnaeus, 1803 (Hemiptera: Reduviidae) no controle natural do pulgãoT.citricidus. De maneira geral, constata-se que, após 48-72 horas de inoculação, o consumo de A. gossypii e M.persicae, infectados pelos fungos entomopatogênicos, é acentuadamente reduzido pelo predador. Após a conidiogênese não ocorreu consumo de presas por $O$. insidosus.

Os resultados da interação hospedeiro-patógenopredador mostraram o comportamento discriminatório de O.insidosus, dependendo do estágio de infecção da doença no hospedeiro. O comportamento característico de $O$. insidosus é o de realizar sondagem do hospedeiro, percorrendo toda a folha de algodão (para A.gossypii) ou pimentão (M. persicae), quando a doença começa apresentar os primeiros sinais. $\mathrm{O}$ baixo consumo de presas infectadas com hifas, blastóporos e após a conidiogênese, é devido à ação de metabólicos tóxicos reconhecido pelo predador (CoHEn, 2000). O predador não se alimentou mesmo com dois dias de inanição. Com o passar do desenvolvimento da doença (72-96 horas eapós conidiogênese), o predador cessa o caminhamento (ficando parado e sem bater as asas), e se mostra longe dos pulgões infectados. Outro comportamento bastante observado foi a limpeza imediata e constante dos tarsos, estilete e antenas, bem como vigoroso batimento das asas. 
Ocomportamentoqueos predadores notratamento testemunha apresentaram foi em algumas atitudes inverso, percorrendo toda a folha de algodão (para $A$. gossypii) ou pimentão (M. persicae), aproximando-se dos pulgõese, logoemseguida, introduzindooestilete. Esse comportamento foi observado porMENDEs(2005), que relatou que é normal o caminhamento por toda a folha com tripes preso ao estilete. Ao completar a alimentação, o predador $O$. insidiosus retira o estilete introduzido na presa, limpa-o com o auxílio do 1 p par de pernas e começa a caminhar novamente, ativando o seu comportamento de busca.

Segundo Mendes (2005), o predador O. insidiosus percorre toda a folha de feijão (Phaseolus vulgaris L., 1753) na procura por Caliothrips phaseoli (Hood, 1877) (Thysanoptera: Thripidae), movimentando a cabeça de um lado para o outro. Quando esse detecta a presa, movimenta as antenas em direção ao tripes e caminha para ele com o rostro estendido.

Concluindo, o consumo de A.gossypii eM.persicae, pelo predador $O$. insidiosus, é reduzido em função da ocorrência de doença fúngica causada pelos patógenos inoculados. Estágios mais avançados da doença fúngica (72-96 horas após a inoculação e na fase de conidiogênese) inibiram sensivelmente o consumo dos pulgões pelo predador. O comportamento evidenciado pelo predador demonstra capacidade discriminatória, capaz dereconhecer a presa infectada pelo patógeno.

\section{REFERÊNCIAS}

BUENO, V.H.P. Controle biológico de pragas: produção massal e controle de qualidade. Lavras: UFLA, 2000. 207p.

COHEN, A.C. How carnivorous bugs feed, In: SCHAEFER, C.W.; PANIZZI, A.R. (Ed.). Heteroptera of economic importance. Boca Raton: CRC Press, 2000. 828p.

DE BORTOLI, S.A.; OLIVEIRA, J.E.M.; SANTOS, R.F.; SILVEIRA, L.C.P. Tabelas de vida de Orius insidiosus (Say, 1832) (Hemiptera: Anthocoridae) predando Aphis gossypii Glover, 1877 (Hemiptera: Aphididae) em diferentes cultivares de algodoeiro. Arquivos do Instituto Biológico, São Paulo, v.75, n.2, p.203-210, 2008.

DUNKEL, F.V.; JARONSKI, S.T. Development of a Bioassay System for the Predator, Xylocoris flavipes (Heteroptera: Anthocoridae), and Its Use in Subchronic Toxicity/Pathogenicity Studies of Beauveria bassiana Strain GHA. Journal Economic Entomology, v.96, p. 10451053, 2003.

FRANÇA, I.W.B.; MARQUES, E.J.; TORRES, J.B.; OLIVEIRA, J.V. Efeitos de Metarhizium anisopliae (Metsch.) Sorok. e Beauveria bassiana (Bals.) Vuill. sobre o Percevejo Predador Podisus nigrispinus (Dallas) (Hemiptera: Pentatomidae). Neotropical Entomology, v.35, p.349-356, 2006.

FUNDERBURK, J.; STAVISKY, J.; OLSEN, S. Predation of Frankliniella occidentalis (Thysanoptera: Thripidae) in field peppers by Orius insidiosus (Hemiptera: Anthocoridae). Environmental Entomology, v.29, p. 376382,2000 .

GENEROSO, A.R. Compatibilidade de Beauveria bassiana e Paecilomyces fumosoroseus com Chrysoperla externa (Neuroptera: Chrysopidae) e metodologia para avaliação da seletividade. 2002. 63p. Dissertação (Mestrado em Entomologia) - Universidade Estadual Paulista, Jaboticabal, 2002.

GOETTEL, M.S.; POPRAWSKI, T.J.; VANDENBERG, J.D.; LI, Z.; ROBERTS, D.W. Safety to nontarget invertebrates of fungal biocontrol agents. In: LAIRD, M.; LACEY, L.A.; DANVIDSON, E.W. (Ed.). Satety of microbial insecticedes. Boca Raton: CRC, 1990. p.209-231.

HALL, R.A. Control of whitefly, Trialeurodes vaporariorum and cotton aphid, Aphis gossypii in glasshouses by two isolates of the fungus, Verticillium lecanii. Annuals of Applied Biology, v.101, p.1-11, 1982.

HOLLING, C.S. Principles of insect predation. Annual Review of Entomology, v.6, p.163-182, 1961.

ISENHOUR, D.J.; YEARGAN, K.V. Effect of crop phenology on Orius insidiosus populations on stripcropped soybean and corn. Journal of the Georgia Entomological Society, v.16, p.310-322, 1981.

JAMES, R.R.; LIGHTHART, B. Susceptibility of the Convergent Lady Beetle (Coleoptera: Coccinellidae) to Four Entomogenous Fungi. Environmental Entomology, v.23, p.190-192, 1994.

JAMES, R.R.; SHAFFER, B.T.; CROFT, B.; LIGHTHART, B. Field evaluation of Beauveria bassiana: its persistence and effects on the pea aphid and a non-target coccinellid in alfalfa. Biocontrol Science and Technology, v.5, p.425-437, 1995.

JARONSKI, S.; LORD, J.; ROSINSKA, J.; BRADLEY, C.; HOELMER, K.; SIMMONS, G.; OSTERLIND; R.; BROWN, C.; STATEN, R.; ANTILLA; L. Effect of a Beauveria bassiana-based mycoinsecticide on beneficial insects under field conditions. 1998. Brighton Conference. Pest Disease, v.3, p.651-656, 1998.

LOUREIRO, E.S.; MOINO JUNIOR, A. Patogenicidade de Fungos Entomopatogênicos aos pulgões Aphis gossypii Glover e Myzus persicae (Sulzer) (Hemiptera: Aphididae). Neotropical Entomology, v.35, p.660-664, 2006.

MAGALHÃES, B.P.; LORD, J.C.; WRAIGHT, S.P.; DAOUST, R.A.; ROBERTS, D.W. Pathogenicity of 
Beauveria bassiana and Zoophthora radicans to the Coccinellid Predators Coleomegilla maculata and Eriopis connexa. Journal Invertebrate Pathology, v.52, p.471-473, 1988.

MAGALHÃES, B.P.; MONNERAT, R.; ALVES, S.B. Interações entre entomopatógenos, parasitóide e predadores. In: ALVES, S.B. (Ed.). Controle microbiano de insetos. 2.ed. Piracicaba: Fealq, 1998. cap. 7, p.195-216.

MENDES, S.M.; BUENO, V.H.P.; CARVALHO, L.M.; REIS, R.P. Custo da produção de Orius insidiosus como agente de controle biológico. Pesquisa Agropecuária Brasileira, v.40, p.441-446, 2005.

MESQUITA, A.L.M.; LACEY, L.A.; CEIANU, C.S.; DABIRE, R. Predatory and Parasitic Activity of Aphelinus asychis (Hymenoptera: Aphelinidae) Following Exposure to the Entomopathogenic Fungus Isaria fumosorosea (Deuteromycotina: Hypomycetes) Under Different Humidity Regimes. Anais da Sociedade Entomológica do Brasil, v.28, p.661-673, 1999.

OLIVEIRA, J.E.M.; DE BORTOLI, S.A.; SANTOS, R.F.; SILVEIRA, L.C.P. Efeito de cultivares de algodoeiro sobre a biologia e capacidade predatória de Orius insidiosus (Say, 1832) (Hemiptera: Anthocoridae) predando Aphis gossypii Glover, 1877 (Hemiptera: Aphididae). Arquivos do Instituto Biológico, São Paulo, v.75, n.1, p.45-52, 2008.

PEÑA-MARTÍNES, R. Biologia de afidos ysu relacion com la transmision de virus. In: URIAS-M, C.; RODRÍGUEZ, M.R.; ALJANDRE, A.T. (Ed.). Afideos como vetores de virus en México. Cidade do México: Centro de Fitopatologia, 1992. v.1, p.11-35.
PESSOA, L.G.A.; CAVALCANTI, R.S.; MOINO JUNIOR, A.; SOUZA, B. Compatibilidade entre Beauveria bassiana e o predador Chrysoperla externa em laboratório. Pesquisa Agropecuária Brasileira, v.40, p.617-619, 2005.

PLANET NATURAL. Natural products for home, lawn and garden. Cataloque, Bozeman, Montana, 2001. 45p.

POPRAWSKI, T.J.; CARRUTHERS, R.I.; SPEESE, J.; VACEK, D.C.; WENDEL, L.E. Early-season applications of the fungus Beauveria bassiana and introduction of the hemipteran predator for control of Colorado potato beetle. Biological Control, v.10, p.48-57, 1997.

RAKAUKAS, R. Hemiptera (Nabidae, Anthocirdae, Miridae) as predators of aphids feeding on fruit and berry plantations in the Lithuanian SSR. Darb. Liet. TSR. Mokslu. Akad. Series C, v.2, p.45-49, 1984.

RICHARDS, P.C.; SCHMIDT, J. The effect of selected dietary supplements on survival and reproduction of Orius insidiiosus (Say) (Hemiptera: Anthocoridae). Canadian Entomologist, v. 128, p.445-447, 1996.

RIUDAVETS, J. Predator of Frankliniella occidentalis (Perg.) and Thrips tabaci. Lind.: a review. Waegen. Agricultural University Papers, 1995. v.95, p.43-87.

VAN LENTEREN, J.C. A greenhouse without pesticides: fact or fantasy? Crop Protection, v.19, p.375384, 2000.

Recebido em 20/10/07

Aceito em 19/11/08 